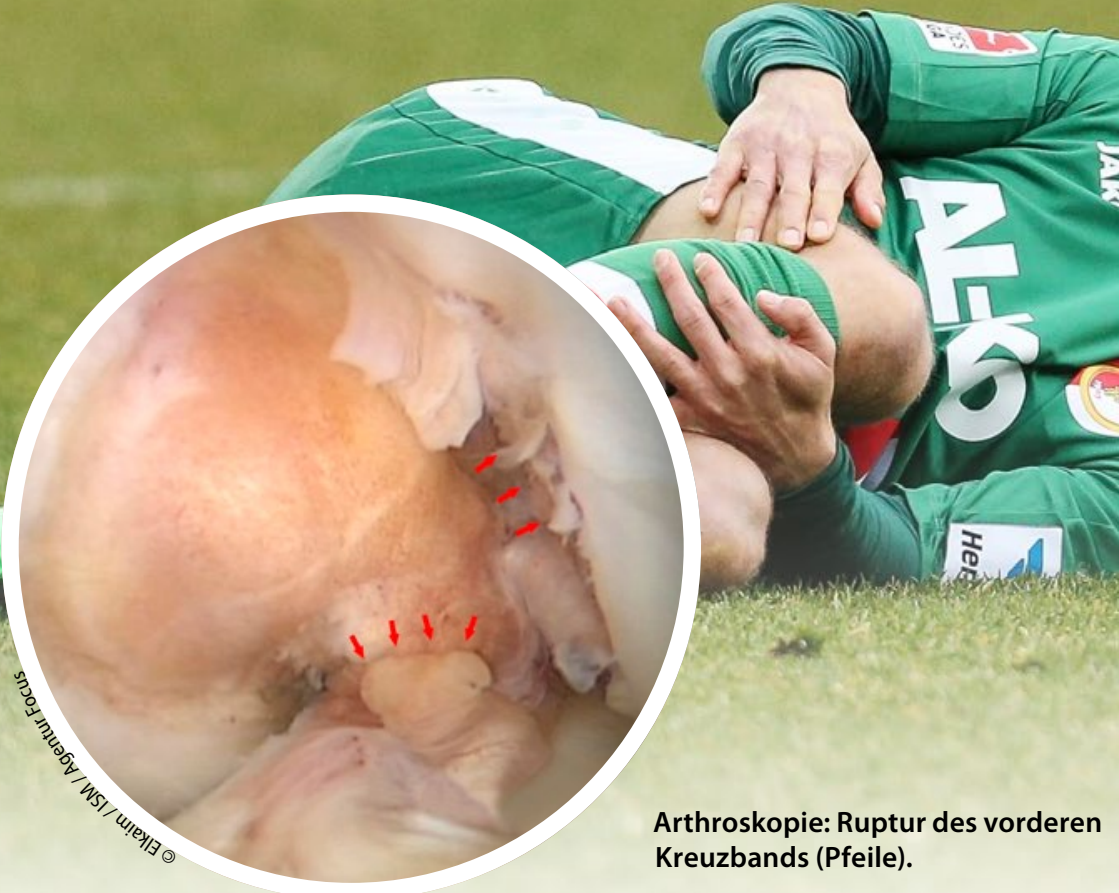

Bis zu 23\% der Verletzungen betrafen die Kniegelenke. Wer den anatomischen Mut aufbringt, darf das Knie ruhig als die Achillesferse des Fußballers bezeichnen. Besonders gefürchtet sind Risse des vorderen Kreuzbandes. Solche Rupturen können Berufskicker monatelang außer Gefecht setzen, und es ist keineswegs immer gewiss, dass sie ihrer Arbeit danach wieder so nachgehen können, wie sie das vorher taten.

\section{Mit dem Kreuzband reißt oft der Karrierefaden}

Das hat kürzlich eine schwedische Studie bestätigt [2]. Wissenschaftler der
Fußballforschungsgruppe der Universität Linköping hatten dafür in den Jahren 2001-2015 insgesamt 78 Profiklubs der höchsten Ligen von 16 europäischen Ländern begleitet und Daten von insgesamt 4.443 Spielern gesammelt. Während dieser Zeit registrierten die Wissenschaftler 157 Verletzungen der vorderen Kreuzbänder: 140 komplette und 17 Teilrupturen. Die Verletzungsgefahr während eines Spiels war 20-mal so hoch wie das Risiko im Training.

138 Spieler mit komplettem Kreuzbandriss unterzogen sich einer Rekonstruktionsoperation. 134 Fußballer konnten nach im Median 6,6 Monaten das
Training wieder aufnehmen, doch bei neun von ihnen gab es bereits vor dem ersten Matcheinsatz Komplikationen: Fünfmal riss das Band erneut, viermal musste das Knie aus anderen Gründen nochmals operiert werden. Drei Jahre später spielten noch $85,8 \%$ der Spieler nach einer Kreuzbandplastik Fußball, aber nur $65 \%$ taten dies auf dem gleichen Niveau wie vor der Verletzung.

\section{Im Tor ist es am sichersten}

Welche Position ein Spieler innerhalb einer Mannschaft einnimmt, beeinflusst sein Verletzungsrisiko erheblich. Eine Untersuchung der Verletzungsmuster

\title{
Übles Foul von SARA
}

Der Grund für lädierte Kniegelenke von Fußballspielern ist nicht immer im Einsatz Mann gegen Mann zu suchen. Manche Beschwerden sind offenbar auf das Spiel Mann mit Frau zurückzuführen. Das legt eine Studie nahe, für die Paul Oyudo vom Queen Mary and Westfield College in London zehn Sportler mit langwierigen Knieproblemen untersucht hat und deren Ergebnisse seinerzeit Aufsehen verursachten [New Scientist, 7. August 1999]. Sechs der Sportler waren Fußballer, fünf spielten in der höchsten englischen Liga.

Die Knieprobleme der Kicker, die im Durchschnitt bereits seit acht Monaten pausieren mussten, hatten zwar mit einer bestimmten Form körperlicher Aktivität zu tun. Um Fußball handelte es sich aber nicht. Vielmehr ging es um Sex, genauer: um viel Sex und eine dabei erworbene reaktive Arthritis (sexually acquired reactive arthritis, SARA). Bei acht der zehn Patienten stellte Oyudo eine Urethritis fest, drei Männer hatten trüben Harn, bei zweien gelang ein Chlamydiennachweis.

Warum SARA gerade Fußballern so häufig ans Knie schießt, dafür hatte Oyudo eine simple Erklärung: „Fußballer haben viel Geld und eine Menge Freizeit" - und damit ausgiebig Gelegenheit, eine spezielle Art des Zweikampfs zu praktizieren.

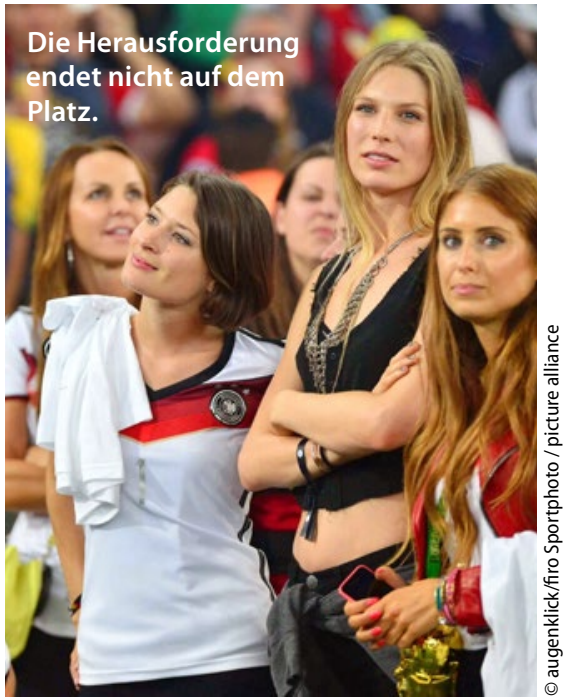

